Document downloaded from:

http://hdl.handle.net/10251/99048

This paper must be cited as:

Vedreño Santos, FJ.; Riera-Guasp, M.; Henao, H.; Manuel Pineda-Sanchez; Rubén PuchePanadero (2014). Diagnosis of Rotor and Stator Asymmetries in Wound-Rotor Induction Machines Under Nonstationary Operation Through the Instantaneous Frequency. IEEE Transactions on Industrial Electronics. 61(9):4947-4959. doi:10.1109/TIE.2013.2288192

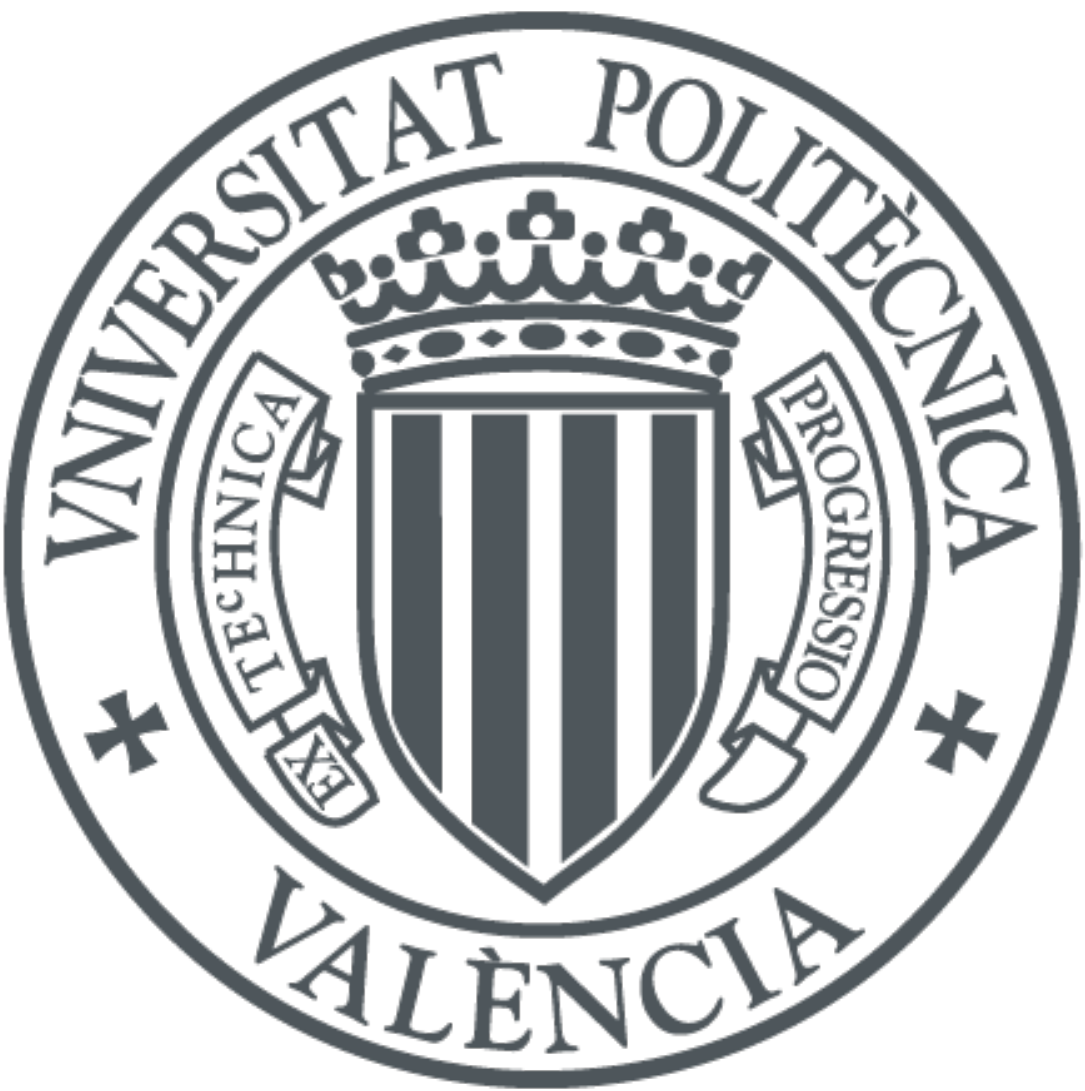

The final publication is available at

http://doi.org/10.1109/TIE.2013.2288192

Copyright Institute of Electrical and Electronics Engineers

Additional Information 


\title{
Diagnosis of Rotor and Stator Asymmetries in Wound Rotor Induction Machines under Non- Stationary Operation through the Instantaneous Frequency
}

\author{
Francisco Vedreño-Santos, Martín Riera-Guasp, Senior Member, IEEE, Humberto Henao, Senior Member, IEEE, \\ Manuel Pineda-Sánchez, Member, IEEE, Rubén Puche-panadero, Member
}

\begin{abstract}
This paper proposes a methodology to improve the reliability of diagnosis of different types of faults in wound rotor induction generators which work under variable load conditions, as in wind turbines applications; the method is based on the extraction of the Instantaneous Frequency of the fault related components of stator and rotor currents during speed changes caused by non-stationary functioning. It is shown that under these conditions, the Instantaneous Frequency versus slip plots of the fault components are straight lines with a specific slope and y-intercept for each kind of fault. In addition, neither of these patterns are dependent on the machine features, or the way the load changes. In addition, the practical methodology of this technique is introduced for diagnosing two different anomalies: stator winding asymmetry and rotor winding asymmetry. The approach is validated by laboratory tests, for both types of faults in two different kinds of machines.
\end{abstract}

Index Terms-- Analytical signal, discrete wavelet transform, fault diagnosis, Hilbert transform, induction generator, instantaneous frequency, load fluctuating conditions, Time-frequency analysis, wind generation

\section{NOMENCLATURE}

$\varphi \quad$ Phase of analytic signal (deg)

$\phi \quad$ Current phase (deg)

$\omega_{s} \quad$ Supply frequency $(\mathrm{rad} / \mathrm{seg})$

$A \quad$ Instantaneous magnitude of analytic signal

E Energy parameter

$R \quad$ Pearson's Coefficient

$a_{n} \quad$ Wavelet decomposition approximation

$c \quad$ Theoretical y-intercept

$c^{\prime} \quad$ Computed y-intercept

$d_{j} \quad$ Wavelet decomposition detail

$f_{\text {samp }} \quad$ Sampling frequency $(\mathrm{Hz})$

$f_{s} \quad$ Supply frequency $(\mathrm{Hz})$

$f_{\max } \quad$ Maximum frequency where the fault component evolves

\begin{tabular}{|c|c|}
\hline$f_{\min }$ & $\begin{array}{l}\text { Minimum frequency where the fault } \\
\text { component evolves }\end{array}$ \\
\hline$f_{\text {Low }}$ & $\begin{array}{l}\text { Minimum frequency of the bandwidth } \\
\text { extracted by the filter process }\end{array}$ \\
\hline$f_{U p p}$ & $\begin{array}{l}\text { Maximum frequency of the bandwidth } \\
\text { extracted by the filter process }\end{array}$ \\
\hline$f_{\text {saR }}$ & Main stator fault harmonic frequency $(\mathrm{Hz})$ \\
\hline$f_{r a S}$ & Main rotor fault harmonic frequency $(\mathrm{Hz})$ \\
\hline$i$ & Current (A) \\
\hline$i_{F C}$ & Current fault component \\
\hline$m$ & Theoretical slope \\
\hline$m^{\prime}$ & Computed slope \\
\hline$n$ & Wavelet decomposition level \\
\hline S & Slip \\
\hline$t$ & Time (sec) \\
\hline AS & Analytic Signal \\
\hline CWT & Continuous Wavelet Transform \\
\hline DFIG & Double Fed Induction Generators \\
\hline DWT & Discrete Wavelet Transform \\
\hline FS & Frequency Sliding \\
\hline GA & Gabor Analysis \\
\hline HT & Hilbert Transform \\
\hline IF & Instantaneous Frequency \\
\hline MCSA & Motor Current Signature Analysis \\
\hline PLC & Programmable Logic Controller \\
\hline PPT & Polynomial Phase Transform \\
\hline PV & Principal Value \\
\hline WAF & Winding Asymmetry Fault \\
\hline WRIG & Wound Rotor Induction Generator \\
\hline WRIM & Wound Rotor Induction Machine \\
\hline WVD & Wigner-Ville Distribution \\
\hline
\end{tabular}

\section{INTRODUCTION}

$\mathrm{n}$ recent years, the interest in the Wound Rotor Induction Machines (WRIM) has greatly increased in the industrial and scientific environments due to the massive use of These machines as generators in wind turbines units. Generation of electricity through wind is growing fast nowadays; the world capacity of wind energy generation is increasing at a rate of $20-30 \%$ per year [1]; an overall generating capacity of $470 \mathrm{GW}$ is predicted for 2015 [2]. Maximizing the reliability of the wind generators is a mandatory premise to optimize the operation of the wind farms; consequently, predictive maintenance systems for wind generators are being progressively introduced. Up to now, commercial wind turbine condition monitoring systems typically use measurements of temperatures, oil analysis and vibration-based techniques to identify faults in the power groups [3]. Nowadays, the diagnosis through the August 4, 2013

Copyright (C) 2009 IEEE. Personal use of this material is permitted. However, permission to use this material for any other purposes must be

This work was supported by the Spanish "Ministerio de Ciencia e Innovación" in the framework of the "Programa Nacional de proyectos de Investigación Fundamental" (project reference DPI2011-23740)

F.Vedreño-Santos, M.Riera-Guasp, M.Pineda-Sánchez, R.PuchePanadero are with Universitat Politècnica de València, Institute of Energetic Technology, Spain (email: fravedsa@etsii.upv.es, mriera@die.upv.es,mpineda@die.upv.es rupucpa@die.upv.es )

H. Henao is with University of Picardie "Jules Verne" Department of Electrical Engineering (email: Humberto.Henao@u-picardie.fr) 
current monitoring is rarely used in wind power plants, but is recognized as a promising methodology.

Moreover, the fault detection systems in electric motors based on monitoring electrical quantities and advanced signal processing tools have experienced an important development over the years [4]-[12]. This fact suggests the feasibility of developing analogous methods but applied to the machines used in wind generators.

Traditionally, fault diagnosis in electrical motors through current analysis has been based on the Motor Current Signature Analysis (MCSA) method[4]; a huge amount of researches have been carried out for solving the practical problems found in the industrial application of the basic MCSA methodology[5],[6]. More recently, new methods of fault diagnosis based on transient analysis of the stator current have been developed. These methods habitually are based on the startup current analysis, by using time-frequency signal analysis tools [7], [8], [15][18]. The Discrete Wavelet Transform (DWT) [7], [8], [19], Polynomial Phase Transform (PPT) [16], Gabor Analysis (GA) [17], Continuous Wavelet Transform (CWT) [15], Wigner-Ville Distribution (WVD) [18] are examples of the signal analysis techniques which have demonstrated ability to perform diagnostics of different kinds of faults through the analysis of startup current. It is remarkable that optimized techniques proposed in [15] and, [18] enable a wide-band analysis of the startup current, where not only the main related fault component but also high order fault related components can be tracked along the timefrequency plane, enabling reliable diagnosis even in adverse conditions.

It should be noted that although a lot of research is recently being developed on transient diagnostic methodologies, these approaches are still rarely used in industrial environments. Nevertheless, the diagnostic methods discussed previously -based both in steady as in transient startup- cannot be generally applied to wind generators. On the one hand, the diagnosis based on conventional MCSA can lead to good results whenever the wind speed is strictly constant. However, it is not unusual that wind speed fluctuates continuously around an average value and consequently rotor speed fluctuates[9], [10], and produces the current spectrum to smear. This fact complicates the diagnosis, especially when incipient faults are searched. A solution for avoiding the smearing effect is to reduce the testing period, but that leads to a reduction of the frequency resolution of the spectrum and to an increase

, all these methods based on the detection of signal energy increases share some drawbacks, as the load of the fundamental harmonic leakage. Consequently, under nonstrictly constant wind speed, the results given by conventional MCSA methods could be unsatisfactory. On the other hand, the duty cycle of wind turbine generators does not include large electromechanical transients, such as startup or plugging. Therefore, the referenced transient diagnostic methods are not suitable for wind turbine predictive maintenance.

Consequently, new diagnostic approaches should be developed, for fault detection under the particular working conditions of wind generators.

Recently, this task has been addressed by several researchers; some works aim to adapt MCSA methods for diagnosing wind generators, assuming steady state or limited and slow variations of the working load conditions as in[11],[12]. Nevertheless, these approaches cannot be considered as a general method of diagnostic, because they are subjected to a conceptual drawback: they apply a steady state based methodology to machines which usually undergo continuously variable working conditions.

Another trend consists of the use of time-frequency signal analysis tools, taking advantage of the experience supplied by the motor transient analysis based approaches, but adapted to the actual working conditions of the wind turbines, characterized but limited by continuous variations of slip. Recent works which follow this trend are[7], [13], [14], [20]-[24].

In [7] the authors introduce an adaptive algorithm which extracts the fundamental current component from transient waves and then analyze the residual by using the DWT, detecting the faults through the increase of some wavelet coefficients.

A low complexity signal processing technique for cyclic bearing failure detection in Double Fed Induction Generators (DFIG)-based wind turbines, which relies on the variance of the non-stationary current envelope is proposed in [13]. In [14] the authors apply the CWT to the electrical power output signal of a Wound Rotor Induction Generator (WRIG) under non-stationary conditions. This approach consists of calculating the energy in a sliding window and in a limited frequency band or scale range, which theoretically contains the fault component for the nonstationary analyzed regimes.

An approach for detecting stator and rotor asymmetries in WRIG, valid under load transient conditions, is presented in [20]. The approach is based on detecting energy increments from the measured magnitudes (rotor and stator currents) into frequency bands which contain the fault related components.

A similar approach is proposed in [21] and 0; where the authors combine the Frequency Sliding (FS) with the DWT for isolating the fault components in restricted frequency bands in which the energy of current signals is computed.

Essentially, all the aforementioned methods are based on the same principle: the faults are detected through a signal energy increase into a frequency band which includes the fault component in the functioning regimes under analysis. In order to reach a good sensitivity (before calculating the signal energy) a pre-treatment of the tested signal is necessary to isolate the fault component into a frequency band wherein this component is the most prominent one; this is achieved by using or combining different signal analysis tools as Hilbert Transform (HT) [13], [16], [17], DWT [19], [20], CWT [14] or FS [21], [22].

Nevertheless, all these methods based on signal energy increases detection share some weaknesses, as the load dependence of the diagnostic parameters and a poor reliability. This can lead to false positive diagnostics, since they cannot discriminate if a increment of energy is produced by the searched fault or by a noise or other phenomena which are not related to the specific fault under study.

This paper addresses the problem of improving the fault diagnostic reliability of induction machines working under non-stationary conditions and in generator mode, improving the work done in [24] where the method was presented. In this paper, a deeper explanation of the methodology is presented as well as compressive comments of practical application issues of the approach and also, new validations 
by test, carried out on a different machine. The proposed methodology could be applied to the field of the fault diagnosis of wind turbines; in this field, this paper introduces the analysis of the IF in the slip-frequency domain as a technique for improving the reliability of the diagnostic. Unlike the previous commented works, this paper proposes that the diagnosis is not only based on detecting increases of energy in the tested signal but also on the detection of characteristic patterns that the Instantaneous Frequency (IF) of fault components produce in the slip-frequency plane during transients involving speed changes.

Although the IF is proposed as a suitable magnitude for diagnostic purposes in recent papers [25], [26] [32], this paper develops and validates a methodology adapted to the specific wind generators functioning conditions. Comparing with the previous literature in the field of diagnosis, in [25] the IF is used for diagnosing demagnetization faults of a PMSM working as motor, in steady state and also, undergone to wide speed variations; the diagnostic is based on the plots in the time domain of the IF of specific Intrinsic Mode Functions of the stator current; nevertheless no characterization nof these plots in healthy or demagnetized state is given. In [26] the IF is used for diagnosing a bar breakage in a cage motor; the diagnostic is based on the pattern in the slip-frequency plane of the IF of the left sideband during a startup transient, in which speed experience a wide variation and evolves in a predefined way.In [23] the IF is used for diagnosis of mixed eccentricity in cage machines. In contrast to these works, the IF is used here for diagnosing stator and rotor asymmetry faults in wound rotor induction machines working as generator under normal working conditions including small and random speed fluctuations.

This paper is structured as follows: Section II characterizes the frequencies of the fault components that will be used for diagnosis; section III explains the method used for computing the IF from a signal component; section IV introduces the proposed diagnostic method; section V explains the practical methods for extracting the fault components from the tested signal for different types of fault. The experimental validation of the proposed approach is exposed in section VI. Section VII deals with practical issues concerning the application of the proposed approach to wind generators. Finally section VII summarizes the conclusions of the work.

\section{PHYSICAL BASIS}

Winding asymmetry in wound rotor machines is a phenomenon associated with actual faults, such as turn-toturn faults [32] or high resistance connections [22],[33] . These faults cause asymmetry between phase impedances that leads to unbalanced phase currents. As a consequence, a negative-sequence system of currents flow through the windings, producing inverse rotating fields [32]. These inverse fields induce the characteristic harmonic components in the currents of the windings installed at the other side of the airgap.

This work introduces a methodology, based on the wellestablished MCSA theory, for the detection of characteristic patterns of the fault components produced by winding asymmetries, in wound rotor induction machines working under non-stationary conditions. The detection of winding asymmetries is a first stage for the diagnosis of turn-to-turn or high impedance connection faults.

With regard to fault components induced by winding asymmetries, in the literature it has been demonstrated that:

-A stator asymmetry in a wound rotor induction machine substantially increases the amplitude of a series of components in the rotor current spectrum; the frequency of the main of these harmonics is given by 0 :

$$
f_{\text {saR }}(s)=(2-s) \cdot f_{s}
$$

where $f_{s a R}$ is the frequency of the main fault component produced by a stator asymmetry in the rotor current and $f_{s}$ is the supply frequency.

-A rotor asymmetry produces a substantial increase in the amplitude of the lower and upper sideband components of stator currents, which frequencies are given by [22]:

$$
f_{\text {ras }}(s)=(1 \pm 2 \cdot s) \cdot f_{s}
$$

where $f_{\text {ras }}$ is the frequency of the main rotor asymmetry fault related components in the stator current.

Conventional MCSA uses (1), (2) as formulas that give the frequencies at the current spectrum, where the fault components appear when a fault happens. On the contrary, in the proposed approach (1) and, (2) are understood as functions that describe the trajectory of the fault components in the slip-frequency plane when a faulty machine undergoes a transient which involves any speed variation. It is remarkable that these trajectories are straight lines, with a specific slope $m$ and offset $c$ different for each fault, irrespective of the way in which speed varies (increasing, decreasing, oscillating...), the machine's characteristics (rated power, rated voltage, number of pole pairs) or the functioning mode (motor-generator). Thus, the slope and the $y$-intercept constitute very reliable patterns which allow to discriminate the corresponding faults from other phenomena that could cause energy increments into specific frequency bands. The generic representation of the frequency of a fault component $f_{F C}$ versus the slip is given by (3) the general equation of a straight line.

$$
f_{F C}(s)=m \cdot s+c
$$

Table I shows the theoretical values of slope $m$ and offset $c$ associated to the different kind of fault tested in this paper; these figures are obtained by comparing (1) and, (2) with (3).

\section{TABLE I. COEFFICIENTS OF THE S-IF (INSTANTANEOUS FREQUENCY) STRAIGHT LINES OF DIFFERENT KIND OF FAULTS}

\begin{tabular}{|c|c|c|c|}
\hline \multicolumn{2}{|c|}{ Kind of fault } & $\boldsymbol{m}$ & $\boldsymbol{c}$ \\
\hline \multicolumn{2}{|c|}{ Stator Asymmetry } & $-f_{s}$ & $2 f_{s}$ \\
\hline \multirow{2}{*}{ Rotor Asymmetry } & LSH & $-2 f_{s}$ & $f_{s}$ \\
\cline { 2 - 4 } & $\mathrm{USH}$ & $2 f_{s}$ & $f_{s}$ \\
\hline
\end{tabular}

\section{CALCULATION OF THE INSTANTANEOUS FREQUENCY OF A SIGNAL WITH A PREDOMINANT COMPONENT}

In the current paper the IF of the fault components is calculated through the method based on the Analytical Signal (AS) and HT, since it requires moderate computing resources, supplying adequate accuracy. Basically, the method comprises the following steps [26]:

- Calculation of the HT of the signal component

$$
H T\left(i_{F C}(t)\right)=\frac{1}{\pi t} * i_{F C}(t)=P V \frac{1}{\pi} \int_{-\infty}^{+\infty} \frac{i_{F C}(\tau)}{t-\tau} d \tau
$$

where $P V$ denotes Principal Value. 
- Construction of the AS, $\vec{i}_{F C}(t)$, as a complex function with a real part equal to the original function $i_{F C}(t)$, and an imaginary part equal to its HT:

$$
\begin{gathered}
\vec{i}_{F C}(t)=i_{F C}(t)+j \cdot H T\left(i_{F C}(t)\right)=A(t) \cdot e^{j \varphi(t)} \\
A(t)=\left[i_{F C}^{2}(t)+H T^{2}\left(i_{F C}(t)\right)\right]^{\frac{1}{2}} \\
\varphi(t)=\arctan \frac{i_{F C}(t)}{H T\left(i_{F C}(t)\right)}
\end{gathered}
$$

Being $A(t), \quad \varphi(t)$ respectively the instantaneous magnitude (or envelope of the original signal) and the instantaneous phase of the analytic signal.

- Finally, the IF of $i_{F C}(t)$ is obtained as the derivative of the phase of the AS:

$$
I F(t)=\frac{1}{2 \cdot \pi} \frac{d \varphi(t)}{d t}
$$

\section{THE PROPOSED APPROACH}

The method of fault diagnosis under fluctuating load conditions proposed in this paper involves the following steps.

\section{A. Signal Capturing}

Two signals have to be captured: A current and the rotor speed. In the case of rotor asymmetry, the tested current is a stator current. For diagnose of stator asymmetry a rotor current has to be tested. During the time in which these signals are tested, a certain speed change should happen.

\section{B. Current Signal Pre-Treatment,}

Before calculating the IF of a fault component of a tested signal, it is necessary to perform a pre-treatment process for extracting the searched fault component from the signal, similar to those performed in [20]. More accurately, the pre-treatment basically consists of a filtering process which objective is to extract a reduced signal $i_{F C}(t)$ from the signal $i(t)$, constituted by the signal components contained into a limited frequency band, $\left[f_{\text {Low }}, f_{U p p}\right]$, which fulfills two conditions:

(i) The frequency band includes the frequency interval, $\left[f_{\min }, f_{\max }\right]$ where the frequency of the searched fault component moves during the fluctuating load regime in which the current is tested.

(ii) The fault component is predominant in this frequency band.

Fig 1 graphically explains the pre-treatment by filtering: $\left[f_{\min }, f_{\max }\right]$ is the frequency interval in which the frequency of the fault component moves during slip oscillations, and $\left[f_{\text {Low, }} f_{U p p}\right]$ is the frequency band extracted through the filtering process. Clearly no other relevant component in this frequency band exists apart from the fault component. Then the extracted signal $i_{F C}(t)$ can be assimilated to the fault component during the sampled period.

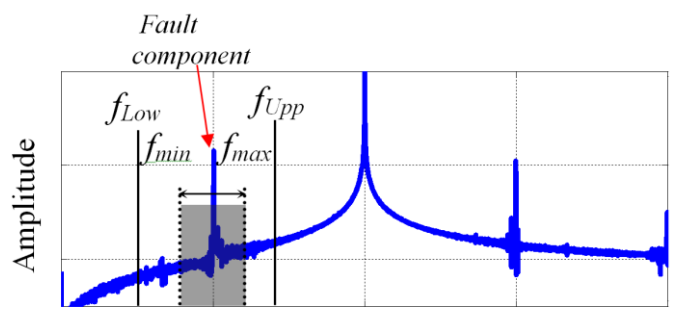

Frequency
The pre-treatment process has to be different for the different kinds of faults, since their associated fault components evolve through different regions of the spectrum. Consequently, the amplitude and relative position of other signal components that could interfere with the calculation of the IF are different in each case.

In this work the pre-treatment of the tested current is carried out using two mathematical tools exclusively, the DWT as filtering tool and the HT, used for shifting the fault components to low frequency regions in order to make easier the fault component extraction in some cases. In the next sub-sections, the properties of these tools, used for extracting the fault components, are briefly discussed.

1) Application of the DWT to the Pre-Treatment of the Current Signal:

The DWT is used for performing efficient low pass filtering processes and extracting the frequency band that contains the fault component.

Provided a certain sampled signal $I=\left(i_{1}, i_{2}, \ldots, i_{N}\right)$ the DWT decomposes it as the sum of $\mathrm{n}+1$ wavelet signals, - an approximation signal $a_{n}$ and $n$ detail signals $d_{j}-$, being $n$ the decomposition level number, which can be set freely:

$$
I=d_{1}+d_{2}+\ldots+d_{n}+a_{n}
$$

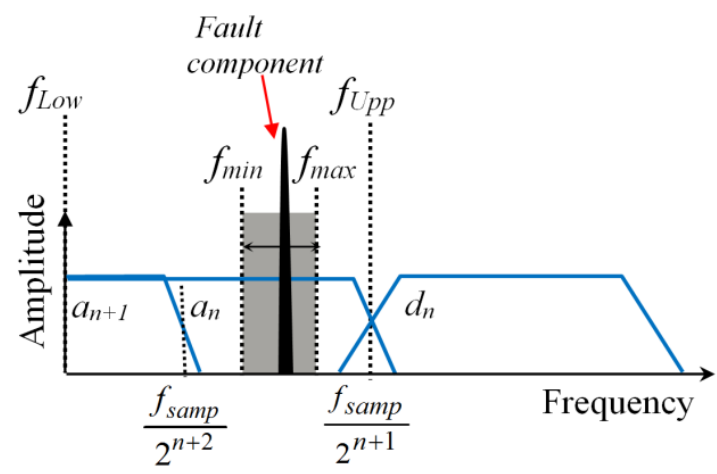

Fig 2. Characterization of the DWT decomposition level for extracting a fault component

The practical procedure for the application of DWT is known as Mallat's algorithm [27] or Subband Coding algorithm; Mallat's algorithm shows that each wavelet signal is associated with a certain frequency band. If $f_{\text {samp }}$ is the sampling rate, in samples per second, used for capturing $I$, then, the $a_{n}$ approximation signal includes the low frequency components of the signal, belonging to the interval $\left[0,2^{-(n+1)} \cdot f_{\text {samp }}\right] \mathrm{Hz}[27]$ (Fig.2).

Therefore, given a component $i_{F C}(t)$ of $I$ which reaches a maximum frequency $f_{\max }$, the highest level approximation $a_{n, \max }$ which contains the component $i_{F C}(t)$ is characterized by:

$$
n_{\max }=\operatorname{integer}\left[\frac{\log \left(f_{\text {samp }} / f_{F C \max }\right)}{\log (2)}-1\right]
$$

Approximation $a_{\text {max }}$ brings the strongest low pass filter of the signal but keeping the component $i_{F C}(t)$ unchanged.

2) Application of the HT to the pre-treatment of the current signal

Depending on the diagnosed fault, the filtering process might not be directly performed due to interferences with other frequency components. This case arises, for example, in the diagnosis of rotor asymmetries due to the proximity of the fault sideband components to the supply frequency.

The fault components to be extracted (diagonal lines 
areas) and the supply frequency (black square) is shown in Fig 3.a.

Due to the DWT filter's features, it may happen that the fault component cannot be split away from the supply frequency; approximation $a_{n}$ does not contain any frequency where the fault component evolves, $a_{n-1}$ only contains the half of the fault component evolution and $a_{n-k}$ contains the whole fault component evolution but also the supply frequency (Fig 3.a), then the frequency bandwidth , which can be extracted, does not fulfill the previously stated condition (ii).

To perform the extraction of the fault component, a frequency shifting must be done by means of the HT.

In [28] is demonstrated that all the components contained in the signal $i(t)$ also appear in the squared magnitude of the AS, after applying the HT, but with a shifted frequency $f_{l}$, being $f_{l}$ the frequency of the predominant component.

If the signal $i(t)$ is the stator current of an induction machine with a rotor asymmetry fault, the sideband harmonics $(1-2 \cdot s) \cdot f_{s},(1+2 \cdot s) \cdot f_{s}$ (Fig 3.a, diagonal lines' areas) will appear in the spectrum of the squared AS magnitude, merged in a unique component with frequency equal to $2 \cdot s \cdot f_{s}$ (Fig 3.b, grey solid area) after being shifted $f_{s}$. As a consequence of the shifting process, the fault components are located at the spectrum low frequencies where the DWT filter performs a better filtering process.

In spite of the fact that the DWT filter bands have not been changed (Fig 3), the extraction of the shifted fault component (Fig 3.b, grey solid area) is possible now by subtracting the approximation $a_{n}$ from the approximation $a_{n-2}$. Note that this process leaves the supply frequency away from the extracted frequency band and both conditions (i) and (ii) are successfully achieved.

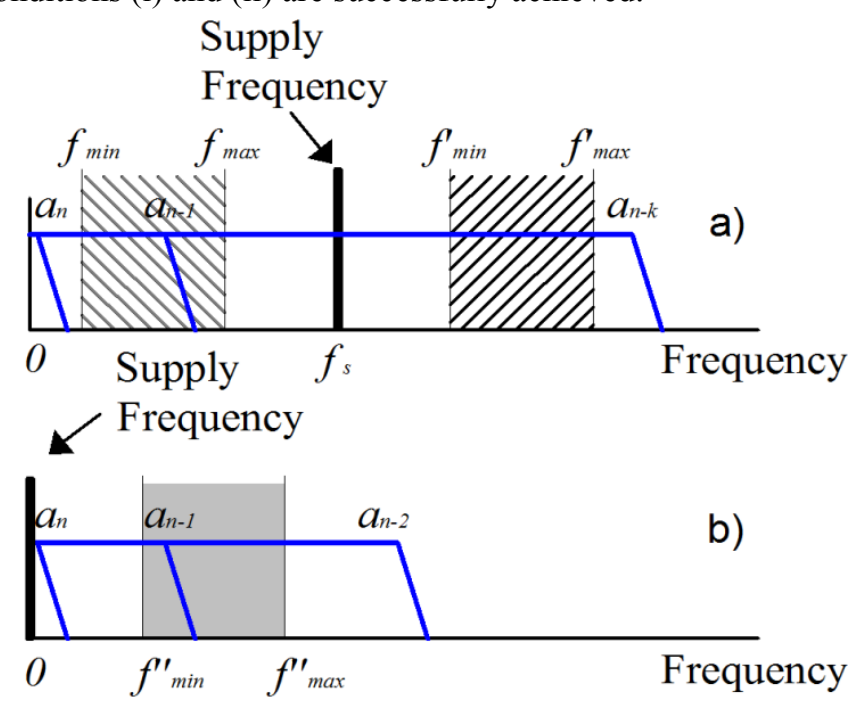

Fig 3. Current frequency shifting as a consequence of applying the HT. a) Current Spectrum before applying the HT b) Current Spectrum after applying the HT

Finally, the theoretical pattern of the rotor asymmetry in the slip-frequency plane, when AS is used, changes to a straight line with the same slope $m=2 \cdot f_{s}$ but with a new $\quad \mathrm{y}$ intercept $c=0$.

\section{Calculation of the IF of the fault component}

Once the process for the extraction of the fault component $i_{F C}(t)$ has been performed, the IF of this signal is calculated applying to it successively (4), (5), (6), (7) and (8), as described in Section III. Due to the effect of the derivative on a tested signal, the calculated IF is usually undergone to strong high frequency noise; but this noise can be easily suppressed by means of a soft low pass filter.

\section{Diagnostic Decision: Analysis of the Slip-IF Pattern}

The proposed criterion to decide whether a specific kind of fault exists or not, consists of comparing the calculated sIF distribution with the theoretical straight line corresponding to the fault (see section II), This comparison can be carried out in two different ways: (i) In a qualitative way, by superposing on a graph the set of $s-I F$ points computed from tested data and the theoretical line; (ii) Based on an objective criterion carried out through the evaluation of figures obtained from a simple statistical analysis of the calculated set of $(s-I F)$ points.

\section{1) Qualitative criterion}

The qualitative method relies on the superposition on a graph of the set of $s-I F$ points computed and the theoretical line as it is shown in Fig 4. When a small degree of fault exists, the set of points tends to concentrate onto the theoretical line (Fig 4.b), whereas they spread away when the machine is in healthy state (Fig 4.a).

\section{2) Quantitative criterion}

Despite the advantages of the qualitative criterion (namely simplicity, intuitive understanding and diagnostic

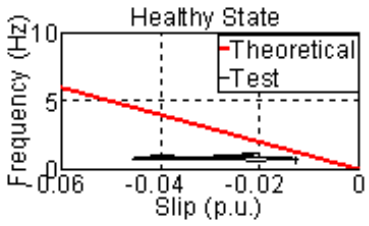

a)

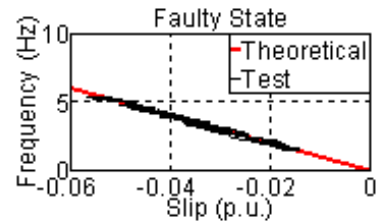

b)
Fig 4. Qualitative criterion

reliability) its use always raises the question of when the computed $s-I F$ points are close enough to the theoretical ones. Moreover, it is difficult to apply it in automated mode without an expert human evaluation; these issues make advisable the development of a quantitative criterion.

The proposed quantitative criterion is based on the computation of the slope $m^{\prime}$, and the y-intercept $c$ ' which define the straight line which fit better with the calculated cloud of points $\left(s_{i}-I F_{i}\right)$ :

$$
\text { IF }=m^{\prime} \cdot s+c^{\prime}
$$

The quantitative criterion also relies on a statistical indicator $R$, which informs about the quality of the approach as well as in a parameter $E$, which takes into account the energy of the signal $i_{F C}(t)$, defined in a way similar to [20] and [21], which is useful for evaluating the severity of the fault.

\section{a) Slope and y-intercept computation}

In this paper, $m^{\prime}$ and $c^{\prime}$ are calculated using the simple linear regression analysis of the calculated $\left(s_{i}-I F_{i}\right)$ set of points, based on the least squares estimation method [29]:

\section{b) Correlation coefficient computation}

Once the simple linear regression approach has been done an indicator, that measures the quality of the approach, is needed.

There are some correlation coefficients in the technical literature such as Pearson's Coefficient, Spearman's Coefficient and Kendall's Coefficient [30]. In the current paper, the Pearson's Coefficient is chosen to measure the 
quality of the simple linear regression performed in the previous subsection.

c) Diagnosis decision by using the quantitative criterion

According to (1) and (2) for a supply frequency of 50 $\mathrm{Hz}$, the theoretical values of slope and y-intercept for each evaluated fault in the current paper are given in Table II.

TABLE II. COEFFICIENTS OF THE S-F STRAIGHT LINES OF DifFERENT KIND OF FAULTS

\begin{tabular}{|c|c|c|}
\hline Kind of fault & m & c \\
\hline Stator Asymmetry & -50 & 100 \\
\hline Rotor Asymmetry & -100 & 50 \\
\hline
\end{tabular}

Therefore, the quantitative criterion will stand as a positive when the computed values of slope $m^{\prime}$ and $\mathrm{y}$ intercept $c^{\prime}$ are close to the theoretical ones given in Table II (that is to say, the relative errors related to its theoretical values are smaller than a predefined threshold) and the value of the correlation coefficient is close to 1 (differs from 1 less than a predefined value).

\section{E. Evaluation of the severity of the fault through the fault component energy}

Once the fault is diagnosed, the degree of severity is evaluated by calculating the energy of the fault component, that is, the energy of the signal $i_{F C}(t)$ resulting of the pretreatment described in subsection $B$ in a similar way as it is done in [20] and, [21]:

$$
E=\sum_{i=1}^{N} \frac{i_{F C i}^{2}}{i_{i}^{2}}
$$

Note that a difference from [20] and, [21] is that here the energy parameter is used only for quantification and not for deciding whether the fault exists or not.

\section{PRE-TREATMENT OF THE TESTED CURRENT BEFORE} EXTRACTING S-IF PATTERN OF THE FAULT COMPONENTS

This section describes the specific pre-treatments of the current signal used in this paper for the different kind of faults which are tested in Section VI. The tested induction machines work as generator, under normal load conditions but undergoing load fluctuations; thus, the slip variations are limited between $s=0$ (no load) and $s= \pm s_{r}$ (rated load). Obviously, different procedures can be used for achieving the objective of isolating the searched fault component into a frequency band. In this paper simple methods with low computational cost are proposed for achieving this goal; in special situations (for example when a double fault exists) the pre-treatment process would become more complicated. The pre-treatment methods will be introduced following an order of increasing complexity.

\section{A. Signal pre-treatment for diagnosing stator asymmetry in wound rotor machines}

For the specified working conditions, (1) indicates that the stator asymmetry fault component in the rotor current moves in the frequency band $\left[\left(2-s_{r}\right) \cdot f_{s}, 2 \cdot f_{s}\right]$-nearly twice the supply frequency -whereas the main component rotor current moves into the band $\left[0, s_{r} \cdot f_{s}\right] \mathrm{Hz}$. Consequently, for this kind of fault, the predominant fault component signal $i_{F C}(t)$ is calculated as (see Fig. 2):

$$
i_{F C}(t)=a_{n S A \text { max }}-a_{n R M \text { max }}
$$

where $a_{n \text { SAmax }}$ is the approximation of higher order that contains the frequency $2 \cdot f_{s}$ and $a_{n R M \max }$ the approximation of higher order which contains the frequency $s_{r} \cdot f_{s}$. The decomposition levels $n_{\text {SAmax }}$ and $n_{R M \max }$ are calculated by substituting $f_{\max }=2 \cdot f_{s}$ and $f_{\max }=s_{r} \cdot f_{s}$ respectively in (10).

\section{$B$. Signal pre-treatment for diagnosing rotor} asymmetry

Under the specified working conditions, when a rotor asymmetry fault exists, the frequency of the sideband harmonics and the fundamental component, in the stator current, always differ less than $2 \cdot s_{r} \cdot f_{s} \mathrm{~Hz}(2)$. When the fault related components are too close to the supply frequency it is not possible to isolate them by applying a simple DWT filter. In this case a slightly more complex pre-treatment is needed. In this paper, a two-step pre-treatment is proposed, similar but simpler than that in [21] and, 0 . The first step consists of calculating the squared magnitude of the AS obtained from the tested signal. The squared magnitude of the $\mathrm{AS}-$ or squared tested current envelope $-A^{2}(t)$, is basically constituted by two components: (i) a low frequency component with large amplitude, produced by the changes that load fluctuations cause in the amplitude of the fundamental component of $i(t)$, and (ii) a component with frequency equal to $2 \cdot s \cdot f_{s}$ originated by the fault. In the second step, the DWT is applied to the squared magnitude of the AS. Although the difference in Hertz among the frequencies of both components is the same in the tested current in comparison to the squared magnitude of AS, in $A^{2}(t)$ both components are located in the low frequency region of the spectrum; this fact enables us to isolate them through the DWT, in a similar way as it has been described in the previous subsection. The fault component, in the case of rotor asymmetry, is finally estimated as:

$$
i_{F C}(t)=a_{n R A \max }-a_{n L F \max }
$$

where $a_{n R A \max }$ is the approximation of higher order which contains the frequency $2 \cdot s_{r} \cdot f_{s}$ and $a_{n L F m a x}$ the approximation of higher order which contains the highest frequency that can reach the component produced by the load fluctuations; this frequency depends on the load fluctuation rate, and for actual wind generators is assumed to be very low (less than $1 \mathrm{~Hz}$ ). As in the previous subsections, the decomposition levels $a_{n R A}$ and $a_{n L F}$ are obtained from (10), by substituting $f_{\max }=2 \cdot s_{r} \cdot f_{s}$ and $f_{\max }=0.5 \mathrm{~Hz}$ respectively.

The pre-treatment performed on the stator currents to extract the fault components changes the theoretical value of the $y$-intercept for the straight line which characterizes while the slope value remains as it is in Table II. The value of the $y$-intercept becomes 0 according to the previous explanations and the slope value remains the value of 100 for a $50 \mathrm{~Hz}$ frequency supply.

\section{EXPERIMENTAL VALIDATION OF THE APPROACH}

Two different machines have been tested to provide the results for the current paper.

The tested machine type 1 is an universal laboratory machine, arranged as a wound rotor induction machine, tested under rotor and stator asymmetry conditions and working under generator mode.

The tested machine type 2 is a commercial wound rotor machine, tested under rotor asymmetry condition and working as generator mode. The detailed characteristics of both machines are given in the Appendix.

The electrical scheme of the test rig is shown in Fig.5 and Fig.12. The tested induction machine was directly coupled to a DC machine which drives it over the synchronous speed in order to get generator functioning. The field winding of the DC machine was fed through a 
motorized rheostat, controlled by a Programmable Logic Controller (PLC). This assembly enabled us to program fixed sequences of speed fluctuations (see Fig 6.a, Fig.14); thus, it was possible to test the machine under different fault conditions but keeping for all the tests the same fluctuating load conditions and making easy to compare the results. The current was measured through a current clamp $(10 \mathrm{~A}-100 \mathrm{mV})$, and the speed through a 360 pulse/turn encoder, connected to a Yokogawa DL 750 digital oscilloscope (16 bit AD converter). The oscilloscope was connected via intranet network to a PC, where the captured signal was processed.

\section{A. Tests on Machine type 1 working as generator}

Two series of tests were carried out on this machine, for validating the approach under primary and secondary winding asymmetry conditions.

\section{1) Diagnostic of secondary winding asymmetry}

The electrical scheme that was set up for this series of tests is shown in Fig 5. Due to practical restrictions, the rotor windings had to be used as primary winding, connected to a three-phase supply source of $160 \mathrm{~V}$. The stator windings were short-circuited working as secondary winding. Additional resistances $R_{A s}$, between 4.15 and 0.07 Ohm (see Table III), were connected in series to a stator

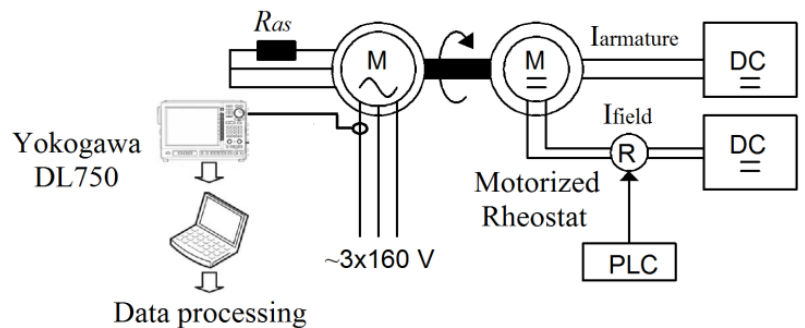

Fig 5. Rotor asymmetry setup scheme

phase for simulating secondary winding asymmetry faults with different severity degrees. A sampling frequency $f_{\text {samp }}=5 \mathrm{kHz}$ was set. The sampling rate was selected with the possibility of using the tested signals eventually in other types of analysis in mind, though for this specific study it might have been set much lower.

The experimental study is divided in two steps: first, the proposed diagnostic method is applied step by step for the case of maximum asymmetry $\left(R_{A s}=4.15 \Omega\right)$, commenting all the details for its application and intermediate results, in order to facilitate the understanding of the proposed method. In the second step the results of ten tests with different additional values of $R_{A s}$ and the same speed profile are exposed in order to determine what the minimum fault the instantaneous frequency method is capable of diagnosing.

The performance of the proposed approach for secondary Winding Asymmetry Fault (WAF) detection is evaluated in non-stationary condition, realized by imposing the speed fluctuation shown in Fig 6.a to the induction
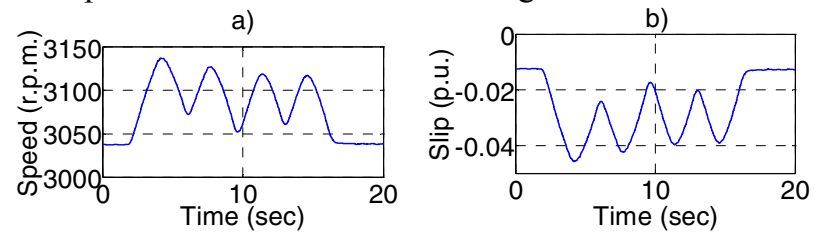

Fig 6. Non-Steady Automated Speed impossed to the Machine type 1 working under generator mode a), correponding slip evolution b).
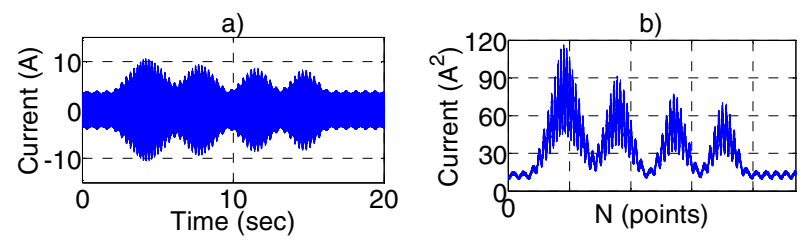

Fig 7. Tested primary current. Machine type 1, generator mode, fluctuating speed, under secondary assymetry $\left(R_{A s}=4.15 \mathrm{Ohm}\right)$ a). Squared amplitude of the analitical signal of the tested stator current. Case of rotor asymmetry, $R_{A s}=4.15 \mathrm{Ohm} \mathrm{b}$ ).

generator. Fig 6.b plots the evolution of the slip during the test, calculated from the speed signal.

The direct consequence of the imposed transient speed is a transient primary current that cannot be suitably analyzed by means of the FFT. Fig 7.a shows the primary current tested under secondary asymmetry condition, with the additional secondary resistance set to $R_{A s}=4.15 \Omega$

Once both signals (speed and current) are captured, the diagnostic process moves into the Current Signal PreTreatment as described in Section III.

In the case of secondary asymmetry, the first step of the pre-treatment is to calculate the squared amplitude of the analytical signal, from the captured current signal, in order to shift the main supply component from $50 \mathrm{~Hz}$ to $0 \mathrm{~Hz}$ and the main related fault components to the low frequency region; The squared amplitude of analytical signal is shown in Fig 7.b.

The next step consists of filtering the signal of Fig 7.b through the DWT for extracting the fault component. Due to the speed variation imposed to the tested machine, the slip varies into the interval [-0.057, -0.012] (see Fig 6.b) and the fault harmonic is located in the bandwidth [51.22, 55.66] Hz (2). After applying the first step of pretreatment (HT) the fault harmonic is set on the bandwidth $[1.22,5.66] \mathrm{Hz}$ (see section IV.B).

The frequency of $A^{2}$ produced by speed fluctuations is estimated in $0.5 \mathrm{~Hz}$. According to (10), (21), section V.A, and taking into account that $f_{s}=50 \mathrm{~Hz}, f_{\text {samp }}=5 \mathrm{kHz}$ the needed approximations to extract the required harmonic components $a_{R A \max }, a_{\text {LFmax }}$ (see Section V.B.) are approximation $a_{8}$ and $a_{12}$ which are shown in Fig 8.

Subtracting the approximation $a_{12}$ from the approximation $a_{8}$, the signal of Fig 9.a is obtained, free of low frequency oscillations due to load fluctuations; in this case, this signal is set up by the primary current components included [27] into the frequency band $[0.61,9.77] \mathrm{Hz}$. If secondary asymmetry exists, as the fault related component moves into this interval, and no other relevant component is included in it, Fig 9.a reproduces the evolution in time of the fault component for a machine with asymmetry in the secondary winding. On the other hand, if no asymmetry exists, this Fig 9.a reproduces a noise or a mixture of not relevant second order harmonics.
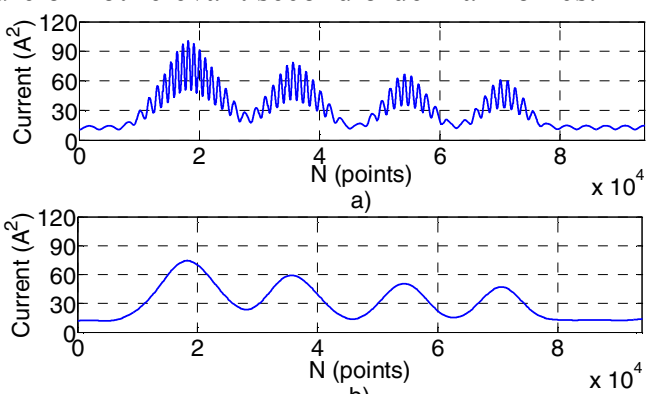

Fig 8. DWT filtering process of signal from 4.b a) Approximation a8 b) Approximation a12 

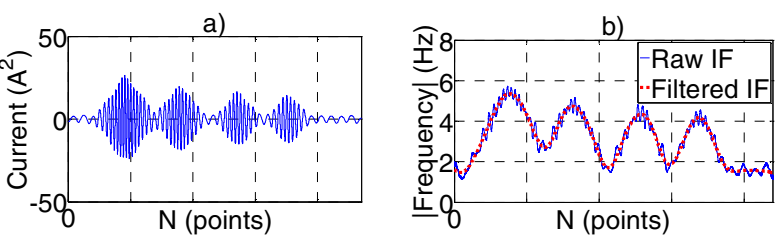

Fig 9. a) Extracted Fault component of the current. Machine Type 1, working as generator with variable rotor speed and rotor assymmetry $\left(R_{A s}=4.15 \mathrm{Ohm}\right)$. b) Raw Instantaneous Frequency (blue line) of the extracted fault component from Fig 9.a and Filtered Instantaenous Frequency (red dotted line)

Once the supposed fault component of the current has been isolated from the rest of uninteresting harmonic components, the IF is calculated according to (8). Due to the derivative applied to compute the IF, the obtained result is noisy, as shown in Fig 9.b.

To overcome the problem of the noise shown in Fig 9.b, a low-pass filter based on the DWT is applied to the raw IF to remove the high frequency harmonics. The filtered IF is presented on Fig 9.b and was obtained as the DWT approximation $a_{10}$ of the raw IF, which contains only the components of IF which frequency is below $2.44 \mathrm{~Hz}$.

The computed IF shown in Fig 9.b does not follow any pattern when it is plotted versus time due to the random evolution of the speed in the time domain. However, as presented in Section I, when the IF is plotted in the slip domain, the IF of the fault component follows a pattern independent of the speed fluctuation. Therefore, the calculated IF shown in Fig 9.b is plotted versus the slip in Fig 10, where also the theoretical s-IF pattern has been superimposed. The comparison of the calculated set of s-IF
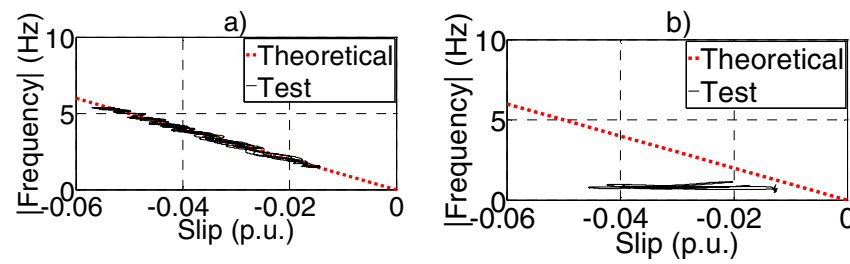

Fig 10. a) Instantaneous Frequency plot for Universal Machine under Rotor Asymmetry fault, working under generator mode. b) Instantaneous Frequency plot for Healthy Machine. Universal Machine working under generator mode.

points and the theoretical s-IF pattern constitute the basis of the qualitative diagnose. In this case, Fig 10.a clearly detects the asymmetry fault, since the calculated s-IF set of points fits perfectly the theoretical pattern of rotor asymmetry fault.

If the same process is followed, but processing the current and speed of the same machines but in healthy condition $\left(R_{A s}=0\right)$, Fig $10 . \mathrm{b}$ is obtained, in which the calculated $s-I F$ set of points is clearly not related with the theoretical pattern, indicating absence of rotor asymmetry fault; Comparing Fig 10.a and Fig 10.b it is shown the good performance of the qualitative approach for discriminating the asymmetric and symmetric machines.

The quantitative analysis results of previous tests are shown in Table III (rows 1-3). Row 1 summarizes the theoretical parameters of the regression analysis; row 2 and 3 give respectively the results corresponding to the tests of healthy machine and asymmetric machine, with a resistance increment in a secondary phase equal to $94.33 \%$ of the original resistance. These figures also clearly discriminate the healthy and faulty machines: for the asymmetric machine the relative error of the calculated slope is equal to $1.3 \%$ related to the theoretical one, whereas in the healthy
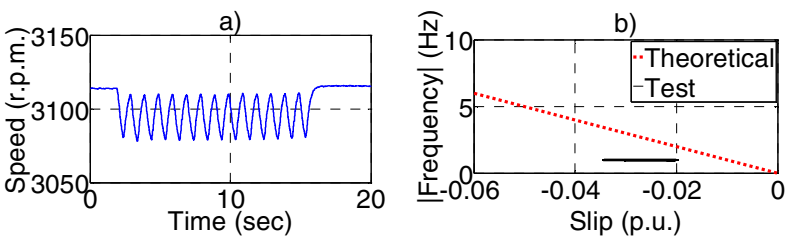

Fig 11. a) Non-Steady Hihg Frequency Speed Fluctuation. Machine type 1 working under generator mode. b) s-IF plot of resulting from the test of a healthy machine undergone to the speed oscillation shown in Fig 11.a

case this error reaches a value of $88.1 \%$. In addition, the correlation coefficient for the asymmetric machine is very near to $1(0.993)$ whereas for the symmetric machine it is reduced to 0.28 .

On the other hand, if the energy parameters resulting from both tests are compared, an increment of ten times in the energy of asymmetric machine related to the healthy one is observed. Nevertheless, based only on this parameter, the cause of the energy increment cannot be established.

In order to demonstrate the reliability of the IF approach, a new test was carried out, wherein the machine was in healthy state but subjected to a High Frequency Speed Fluctuation (HFSF) as shown in Fig 11.a. The aim of this test is also to prove the independence of the diagnostic method from the way in which the speed varies. In this test, the amplitude and frequency of speed oscillation was set in such a way that a strong current component was produced into the same frequency band used for extracting the fault component. As a consequence, the energy parameter calculated from this test reach a very high value (higher than in the case of maximum tested asymmetry), as can be seen in the last row of Table III (Healthy, HFSF). This result would lead to a false diagnose of asymmetric machine if the diagnostic criterion was based on the energy parameter. However, when the IF approach is used, a simple look at the $s-I F$ plot of Fig 11.b or to the calculated slope and correlation coefficient corresponding to this test, enable to discard with high reliability the asymmetry fault in the tested machine.

Note that the $s-I F$ plot of Fig 11.b, except for being useful for discarding the asymmetry fault, also informs of the nature of the perturbation that produces the energy increment: It consists of a component whose frequency is not depending on slip (horizontal line) and has a constant value equal to $1 \mathrm{~Hz}$.

After the three tests described in the previous subsection, eight new tests were carried out by using the same scheme and speed profile but using a different value of the additional resistance $R_{A S}$ in each test (see Table III, columns 2 and 3 ) used for setting out the secondary asymmetry. In this way, the results of the healthy machine can be compared with the results of nine different secondary winding asymmetries, ranging from $94.33 \%$ (test A1) to $1.62 \%$ (test A9) of the original phase resistance and this will give us an order of magnitude of the minimum asymmetry that the approach is able to diagnose.

According to $R$ and $\mathrm{m}^{\prime}$ parameter, IF method is suitable for the diagnosis of secondary winding asymmetries that only increases $5.85 \%$ (test A7) of the rotor winding resistance.

The last column of Table III gives the value of the normalized energy based parameter calculated as in [20]. 
TABLE III. ROTOR WINDING DIAGNOSIS RESULTS. UNIVERSAL MACHINE WORKING UNDER GENERATOR MODE

\begin{tabular}{|c|c|c|c|c|c|c|}
\hline \multirow{2}{*}{ Test } & \multicolumn{2}{|c|}{$\begin{array}{c}\text { Additional } \\
\text { Resistance }\left(\mathbf{R}_{\mathrm{As}}\right)\end{array}$} & \multicolumn{4}{|c|}{ Results } \\
\hline & $\begin{array}{c}\text { Value } \\
\Omega\end{array}$ & $\begin{array}{c}\text { Value } \\
\text { (\%) }\end{array}$ & $\boldsymbol{R}$ & $m^{\prime}$ & $c^{\prime}$ & $E$ \\
\hline Theoretical & & & 1 & 100 & 0 & \\
\hline Healthy & & & 0.285 & 11.87 & 0.600 & 0.15 \\
\hline A1 & $4.15 \Omega$ & $94.33 \%$ & 0.993 & 98.72 & 0.005 & 1.58 \\
\hline $\mathrm{A} 2$ & $2.64 \Omega$ & $60.03 \%$ & 0.995 & 99.42 & 0.014 & 1.15 \\
\hline A3 & $1.73 \Omega$ & $39.38 \%$ & 0.995 & 99.73 & 0.016 & 0.80 \\
\hline A4 & $1.10 \Omega$ & $25.11 \%$ & 0.974 & 105.12 & -0.216 & 0.56 \\
\hline A5 & $0.69 \Omega$ & $15.73 \%$ & 0.958 & 111.54 & -0.511 & 0.37 \\
\hline A6 & $0.43 \Omega$ & $9.67 \%$ & 0.917 & 122.85 & -1.104 & 0.27 \\
\hline A7 & $0.26 \Omega$ & $5.85 \%$ & 0.881 & 114.38 & -1.020 & 0.20 \\
\hline A8 & $0.14 \Omega$ & $3.29 \%$ & 0.493 & 55.89 & 0.060 & 0.16 \\
\hline A9 & $0.07 \Omega$ & $1.62 \%$ & 0.356 & 36.21 & 0.434 & 0.15 \\
\hline $\begin{array}{l}\text { Healthy } \\
\text { HFSF }\end{array}$ & & & -0.317 & -4.12 & 1.097 & 2.01 \\
\hline
\end{tabular}

The normalized energy parameter increases with the degree of fault, but diagnosis based on this parameter lacks of reliability, since -as previously pointed out- it does not provide information about the kind of perturbation that produces it and can lead to false positive diagnosis.

\section{2) Diagnostic of primary winding asymmetry}

The experimental setup for this series of tests is shown in Fig $12\left(\mathrm{U}=300 \mathrm{~V}, \mathrm{~S}_{1}\right.$ open, $\mathrm{S}_{2}$ closed); in this case the stator was used as primary winding, connected to a threephase $300 \mathrm{~V}, 50 \mathrm{~Hz}$ power supply. The asymmetries were produced by connecting a series of resistances $R_{A p}$ to a stator phase, which now acts as primary winding. The speed profile (Fig 6a) was also used in this series of tests. A line current of the rotor $I_{s}$, (acting as short-circuited secondary winding) is measured. A sampling rate $f_{\text {samp }}=2 \mathrm{kHz}$ was used for these tests.

In the case of primary asymmetry, the use of the Hilbert Transform to set the most predominant frequency of the current to $0 \mathrm{~Hz}$ is not needed due to the large distance between the fault component and the fundamental component in the rotor current. Since no relevant harmonics exist near the frequency band in which move the main fault component, the pre-treatment is reduced to a pass-band filter that is performed via DWT.

All the other steps, that have been already shown in the rotor asymmetry test, must be carried out.

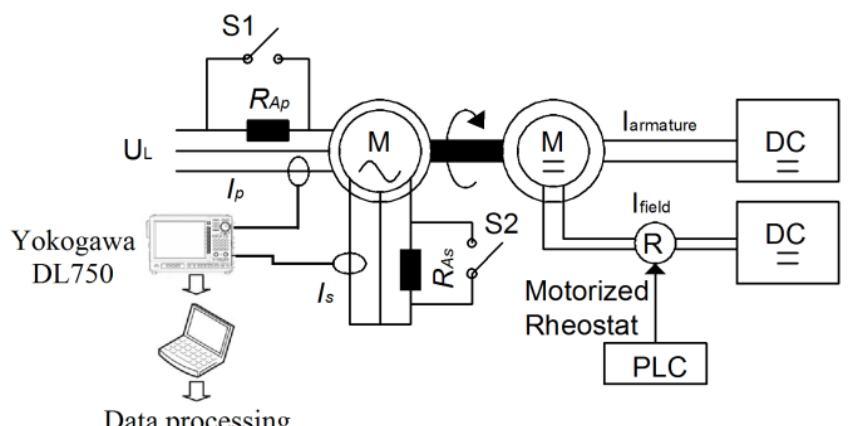

Due to load conditions set on the tested machine, the fault harmonic moves into the bandwidth [100.65, 102.05] Hz. Equation (13) estimates de fault component. The chosen approximations were given by (10) whose values are $a_{3}$ and $a_{7}$.

Fig 13.a and, Fig 13.b plot the calculated and theoretical instantaneous frequency versus the slip under different conditions. Fig 13.a depicts the result when the maximum fault is set on the machine $\left(R_{A p}=4.15 \Omega\right)$. Fig 13.b depicts the result when the machine is healthy. As in the secondary asymmetry tests, the qualitative criterion based in the $s-I F$ plot, clearly discriminate the faulty machines from the healthy machine.
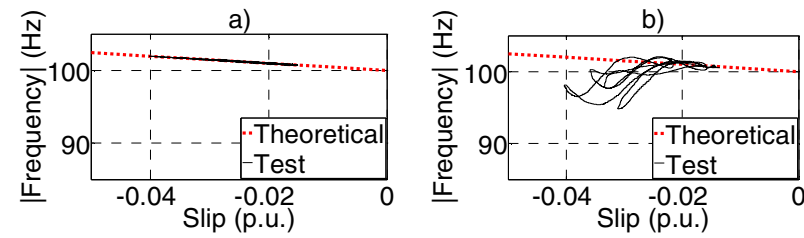

Fig 13. Instantaneous Frequency of the machine type 1 under fluctuating speed operation. Maximum Stator Asymmetry a).Healthy Machine b)

Table IV summarizes the main numerical results got from the test samples. Only the cases of maximum fault set on the machine, the minimum fault which has been reliably diagnosed $\left(R_{a d d} \approx 0.4 \cdot R_{s}\right)$, and the healthy machine and the healthy machine with the high frequency fluctuating speed are shown in table IV.

According to $R$ and $m^{\prime}$ parameter, the IF method can diagnose stator winding asymmetries which increase $40 \%$ of the stator winding resistance.

TABLE IV. STATOR Winding DiAgNOSIS RESUlTS. UNIVERSAL MACHINE WORKING UNDER GENERATOR MODE

\begin{tabular}{|c|c|c|c|c|c|c|}
\hline \multirow{2}{*}{ Test } & \multicolumn{2}{|c|}{$\begin{array}{c}\text { Additional } \\
\text { Resistance (Rap) }\end{array}$} & \multicolumn{4}{c|}{ Results } \\
\cline { 2 - 7 } & $\begin{array}{c}\text { Value } \\
\boldsymbol{\Omega}\end{array}$ & $\begin{array}{c}\text { Value } \\
(\%)\end{array}$ & $\boldsymbol{R}$ & $\boldsymbol{m}^{\prime}$ & $\boldsymbol{c}^{\prime}$ & $\boldsymbol{E}$ \\
\hline Theoretical & & & 1 & 50 & 100 & \\
\hline A1 & $4.15 \Omega$ & 94.33 & 0.961 & 50.57 & 99.98 & 0.56 \\
\hline A3 & $1.73 \Omega$ & 39.38 & 0.868 & 53.12 & 99.89 & 0.32 \\
\hline Healthy & & & -0.655 & -138.14 & 103.21 & 0.16 \\
\hline
\end{tabular}

B. Tests on Wound machine Type 2 working as generator

In this sub-section, the IF approach is validated on a commercial wound rotor induction machine rated $11 \mathrm{Kw}$ with two pole pairs (machine type 2) which characteristics are given in the Appendix. The electrical scheme used for these tests is shown in Fig 12 but in this case the asymmetry is forced in a rotor phase and a stator line current $I_{p}$ is measured $\left(U=120 \mathrm{~V}, S_{1}\right.$ closed, $S_{2}$ open). The induction machine was tested under healthy state and under six different rotor asymmetry conditions reached by connecting additional resistances $R_{A s}$, between 0.69 and $0.02 \mathrm{Ohm}$ (see Table V), in series to a rotor phase through a slip ring; the value of the rotor phase resistance was $R_{r}=0.335 \Omega$. A series of tests were carried out, in mode generator. A sampling frequency $f_{\text {samp }}=5 \mathrm{kHz}$ was set.

Fig 12. Stator asymmetry setup scheme 


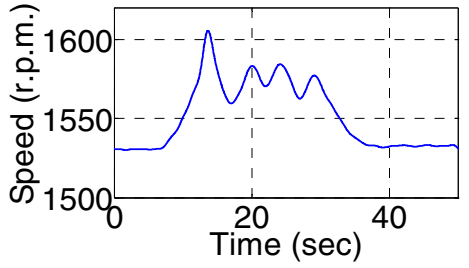

Fig 14. Non-Steady State Automated Speed. Commercial Wound Machine working under generator mode

\section{1) Diagnostic of rotor asymmetry working under} generator mode

Seven automated tests with different additional resistances were carried out under non-stationary condition which was realized by imposing the same speed fluctuation in all tests - shown in Fig 14- to the induction generator. Finally, an additional test, where the machine was in healthy state but subjected to an oscillating speed as shown in Fig 16.a, was carried out with the same purpose as in the previous sub-sections.

Due to the speed variation imposed to the tested machine, the fault harmonic is located in the bandwidth $[52,61.52] \mathrm{Hz}$. After applying the first step of pretreatment (HT) the fault harmonic is set on the bandwidth [2, 11.52] Hz. Equation (14) estimates the fault component and the chosen approximations are given by (10), whose values are $a_{7}$ and $a_{11}$.

Fig 15.a, Fig 15.b and Fig 16.b plot the instantaneous frequency versus the slip obtained for three different tests. Fig 15.a depicts the result when the maximum fault is set on the machine and it can be seen that the computed IF gathers around the theoretical line, whereas Fig 15.b depicts
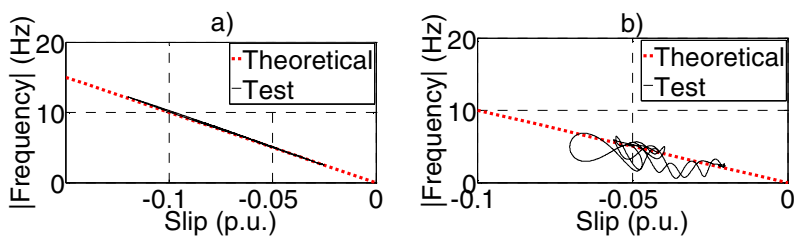

Fig 15. Commercial Machine working under generator mode and fluctuating speed. Instantaneous Frequency with Rotor Asymmetry $\mathrm{R}_{\mathrm{As}}=0.14 \Omega(42 \%)$ a). Instantaneous Frequency for Healthy Machine b).
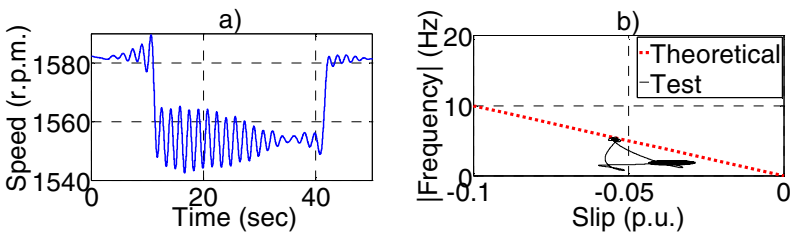

Fig 16. Commercial Machine working under generator mode in healthy state. Non-Steady State High Frequency pulsating speed a). Instantaneous Frequency for Healthy Machine under HFSF b).

the result when the machine is healthy, and it is seen that the computed IF spreads away from the theoretical line. Fig 16.b depicts the result when the machine is healthy but a high frequency fluctuating speed (see Fig 16.a) is set on the machine. In Fig 16.b, where the machine is healthy, it is shown how the computed IF spreads away from the theoretical line; however the bandwidth energy rises related to the healthy case (see Table V) that can lead us into false positives if the diagnostic method only relies on the energy criterion. Interestingly, in Fig 16.b the IF points tend to concentrate around the frequency of $1 \mathrm{~Hz}$, indicating that the transient phenomena that produce the energy increment have a constant predominant frequency, independent of the speed.

Table V summarizes the main numerical results obtained from the test samples, where it is shown that a fault with only a $6 \%$ of increased winding resistance is reliably diagnosed. Apart from that, it is also shown that the healthy test with the high frequency speed fluctuation increases the bandwidth energy $137 \%$ that can mislead into the machine diagnosis if it is exclusively based on the energy criterion.

TABLE V. ROTOR WINDING DIAGNOSIS RESULTS. COMMERCIAL MACHINE WORKING UNDER GENERATOR MODE

\begin{tabular}{|c|c|c|c|c|c|c|}
\hline \multirow{2}{*}{ Test } & \multicolumn{2}{|c|}{ Resistance } & \multicolumn{4}{c|}{ Results } \\
\cline { 2 - 7 } & $\begin{array}{c}\text { Value } \\
\boldsymbol{\Omega}\end{array}$ & $\begin{array}{c}\text { Value } \\
(\%)\end{array}$ & $\boldsymbol{R}$ & $\boldsymbol{m}$ & $\boldsymbol{c}$ & $\boldsymbol{E}$ \\
\hline $\mathrm{A} 1$ & $0.69 \Omega$ & $206 \%$ & 0.999 & -101.20 & -0.0155 & 7.92 \\
\hline $\mathrm{A} 2$ & $0.43 \Omega$ & $128 \%$ & 0.999 & -100.85 & 0.0721 & 6.83 \\
\hline $\mathrm{A} 3$ & $0.26 \Omega$ & $78 \%$ & 0.999 & -101.46 & 0.0131 & 4.58 \\
\hline A4 & $0.14 \Omega$ & $42 \%$ & 0.999 & -101.55 & -0.0614 & 3.90 \\
\hline A5 & $0.07 \Omega$ & $21 \%$ & 0.999 & -102.87 & -0.0891 & 2.76 \\
\hline A6 & $0.02 \Omega$ & $6 \%$ & 0.999 & -103.11 & -0.0325 & 1.04 \\
\hline Healthy & & & 0.722 & -71.51 & 0.6966 & 0.08 \\
\hline Healthy HFL & & & 0.7790 & -121.99 & -2.4318 & 0.19 \\
\hline
\end{tabular}

VII. PRACTICAL REMARKS ON THE APPLICATION OF THE APPROACH TO WIND GENERATORS

Fig 17 depicts the typical control strategy of rotating speed of DFIG generators, as a function of the wind speed, in wind turbines. This strategy is based on four speed regions [31]:

- Region 1(Minimum speed region): for wind speeds between $v_{1} \sim 3 \mathrm{~m} / \mathrm{s}$ and $v_{2} \sim 5 \mathrm{~m} / \mathrm{s}$. The rotational speed is kept constant, equal to $\Omega_{\min }(\mathrm{rad} / \mathrm{s})$. Below $v_{l}$ (cut in wind speed) is not feasible to inject energy to the grid, and the generator is not connected. In this region, the optimal rotational speed (which maximizes energy generation) is smaller than $\Omega_{\text {min }}$, but this minimum value is set for avoiding resonant phenomena in the tower that can be excited for lower rotating frequencies.

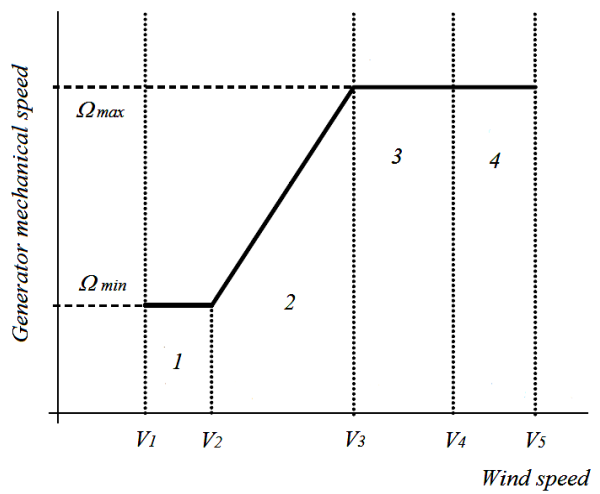

Fig 17. Generator mechanical speed vs Wind speed for a wind turbine control strategy based on four wind speed regions.

- Region 2 (Maximum power tracking region): for wind speeds between $v_{2} \sim 5 \mathrm{~m} / \mathrm{s}$ and $v_{3} \sim 10 \mathrm{~m} / \mathrm{s}$. Above $v_{2}$ the optimal rotating speed is greater than $\Omega_{\text {min }}$. Thus in this region, the control system imposes the optimal rotating speed $\Omega$ for each average wind speed.

- Region 3 (Constant speed partial load region): for wind speeds between $v_{3} \sim 10 \mathrm{~m} / \mathrm{s}$ and $v_{4} \sim 13 \mathrm{~m} / \mathrm{s}$. For wind speed $v_{4}$ the rated rotational speed $\Omega_{\max }$ is reached. $\Omega_{\max }$ is the maximum speed at which the turbine can work permanently without suffering premature damage in the 
blades due to fatigue that the inertial loads would produce. In this region, the mechanical torque produced by the turbine increases with the wind speed; the control system modifies the rotor settings in so that the electromagnetic torque generated by the DFIG balances the mechanical torque, thus producing an increment of the generated power but at constant speed.

- Region 4(Constant speed full load region): for wind speeds between $v_{4} \sim 13 \mathrm{~m} / \mathrm{s}$ and $v_{5} \sim 25 \mathrm{~m} / \mathrm{s}$. For $\left(v_{4}, \Omega_{\max }\right)$ the rated power of the generator is reached. For $v>v_{4}$ the control system modifies the pitch angle of the blades or the yaw angle in such a way that the mechanical torque remains constant although wind speed increases. Thus in this region the DFIG generates its rated power irrespective of the wind speed. Above $v_{5}$ the blades can be damaged by the excessive mechanical forces that they have to deal with; consequently when $v>v_{5}$ the group is disconnected and stopped.

In actual wind farms, wind turbines work most of the time in regions 3 and 4; moreover, in these regions the generated power is substantially greater than in regions 1 and 2. For these reasons, regions 3 and 4 are the most important from a practical point of view.

On the other hand, since the diagnostic methodology which this paper proposes is suited for applications with speed fluctuations, looking at Fig 17 it could be thought that this approach would be only suitable for region 2 . This is not true, as can be easily understood by deeper analysis of the control system operation mode. In fact, there is not conceptual inconvenience for applying the proposed methodology in any of the four regions of Fig 17.

Indeed, Fig 17 is giving the set of points used for the control system for different average wind speeds. In actual operation it is usual that wind speed fluctuates around an average value. Under these conditions, the control system does not react, since the control loop usually contains controllers with hysteresis bands. Under real operation, small wind speed fluctuations lead to small rotating speed fluctuations around the selected reference speed $\left(\Omega_{\text {min }}, \Omega\right.$ or $\Omega_{\max }$ ) irrespective of how the wind turbine works in region $1,2,3$ or 4 . Thus, from a conceptual point of view, the diagnostic methodology can be applied in all the working range of the wind turbine.

\section{CONCLUSION}

This paper introduces a new approach, which increases the reliability of the diagnosis of stator and rotor winding asymmetry in wound rotor induction generators working under non stationary conditions. This methodology is specially promising for wind generators. The proposed methodology relies not only on the detection of signal energy increases in specific frequency bands, but also on the characteristic patterns of the IF of the fault components. This paper demonstrates that under non-stationary regimes, the graphs of the instantaneous frequency of the fault related components in the slip-frequency plane are straight lines. In addition, the slope and y-intercept of these lines are characteristic for each type of fault, and do not depend on the characteristics of the machine, the degree of load or how the speed varies. Therefore, the IF graphics are very reliable patterns for the characterization of the faults; thus, the proposed approach, unlike approaches based exclusively on detecting signal energy increases, has a very low risk of producing false positive diagnostics.
This paper also introduces a methodology for the extraction of the IF of the fault components. The feasibility of the approach is experimentally validated; three series of tests were carried out on two different machines, undergoing continuous and random speed fluctuations. Low levels of asymmetries were reliably diagnosed (up to a $6 \%$ in the case of rotor asymmetry) and discriminated from other phenomena as load fluctuations, that produce false positive diagnostics for the diagnosis base on approaches that rely on the increase of the energy of the signal.

\section{APPENDIX}

Machine type 1: universal machine, arranged as wound rotor three-phase induction machine with the following features: $1.5 \mathrm{~kW}, 50 \mathrm{~Hz}$, two-pole, rated speed $2800 \mathrm{rpm}$ (motor) 3200rpm (generator). Stator winding: $240 \mathrm{~V}$, rated current $5.5 \mathrm{~A}$ star-connected, stator resistance $R_{S}=4.4 \Omega /$ phase ; Rotor Winding: rated Current $8 \mathrm{~A}$, Delta connected, rotor Resistance $R_{R}=10.15 \Omega /$ phase .

Machine type 2: $11 \mathrm{~kW}$, four-pole, rated speed 1480 rpm. Stator winding: $220 \mathrm{~V}$, delta connected, rated current $40 \mathrm{~A}$, stator resistance $R_{S 2}=0.333 \Omega /$ phase. Rotor winding: $310 \mathrm{~V}$, rated current $26 \mathrm{~A}$, star-connected, rotor resistance $R_{r 2}=0.335 \Omega /$ phase

\section{REFERENCES}

[1] "Wordl Energy Outlook 2010", International Energy Agency, ISBN: 978-92-64-08624-1

[2] "Global Wind Energy Council", Chrono Press, ISBN: 978-620-117039-1

[3] Daneshi-Far, G. A. Capolino, H. Henao, "Review of Failures and Condition Monitoring in Wind Turbine Generators", XIX International Conference on Electrical Machines - ICEM 2010, Rome

[4] W. T. Thomson and M. Fenger, "Current signature analysis to detect induction motor faults," IEEE Ind. Appl. Mag., vol. 7, no. 4, pp. 26-34, Jul./Aug. 2001

[5] Y.-H. Kim, Y.-W. Youn, D.-H. Hwang, J.-H. Sun, and D.-S. Kang "High-Resolution Parameter Estimation Method to Identify Broken Rotor Bar Faults in Induction Motors," IEEE Trans. Industrial Electronics, vol. 60, no. 9, pp. 4103-4117, Sept 2013.

[6] A. Bellini, A. Yazidi, F. Filippetti, C. Rossi, G.-A. Capolino, "High frequency resolution techniques for rotor fault detection of induction machines," IEEE Trans. Industrial Electronics, vol. 55, no. 12 , pp.4200-4209, Dec. 2008

[7] H. Douglas, P. Pillay, A.K. Ziarani, "A new algorithm for transient motor current signature analysis using wavelets" IEEE Transactions on Industry Applications, vol. 40, no. 5, pp. 13611368, Sept./Oct. 2004

[8] Ordaz-Moreno, A. ; de Jesus Romero-Troncoso, R. ; Vite-Frias, J.A. ; Rivera-Gillen, J.R. ; Garcia-Perez, A. "Automatic Online Diagnosis Algorithm for Broken-Bar Detection on Induction Motors Based on Discrete Wavelet Transform for FPGA Implementation" IEEE Trans. On Industrial Electronics, Volume: $55, \mathrm{n}^{\circ} 5$, pp.: $2193-2202,(2008)$

[9] F. Filippetti, A.Bellini, G.A. Capolino, "Condition Monitoring and Diagnosis of Rotor Faults in Induction Machines: State of Art and Future Perspectives", Proceedings of the 2013 IEEE Workshop on Electrical Machines Design, Control and Diagnosis,pp.197-207, Paris, March 2013

[10] Muller, S.; Deicke, M.; De Doncker, R.W., "Adjustable speed generators for wind turbines based on doubly-fed induction machines and 4-quadrant IGBT converters linked to the rotor," Industry Applications Conference, 2000. Conference Record of the 2000 IEEE, vol.4, no., pp.2249,2254 vol.4, Oct 2000

[11] S. Toma, L. Capocchi, and G.A. Capolino, "Wound-Rotor Induction Generator Inter-Turn Short-Circuits Diagnosis Using a New Digital Neural Network", Ieee trans. on Iindustrial Electronics, vol. 60, no. 9, pp. 4043-4052, September 2013

[12] A.Stefani, A.Yazidi, C.Rossi, F.Filippetti, D.Casadei, G.A. Capolino, Doubly fed induction machines diagnosis based on signature analysis of rotor modulating signals, IEEE Trans. Ind Appl. 44 (6) (2008) 1711-1721. 
[13] Yassine Amirat1, Vincent Choqueuse, Mohamed Benbouzid1 and Sylvie Turri, "Hilbert Transform-Based Bearing Failure Detection in DFIG-Based Wind Turbines "International Review of Electrical Engineering 6, 3 (2011) 1249-1256

[14] W. Yang, P. J. Tavner, C. J. Crabree, M. Wilkinson, "CostEffective Condition Monitoring for Wind Turbines", IEEE Transactions on Industrial Electronics, Vol. 57, No. 1, pp. 263-271 (2010).

[15] J. Pons-Llinares, J.A. Antonino-Daviu, M. Riera-Guasp, M. Pineda-Sánchez, and V. Climente-Alarcón, "Induction motor diagnosis based on a transient current analytic wavelet transform via frequency B-splines," IEEE Trans. Ind. Electron., vol. 58, no. 5, pp. 1530-1554, May 2011.

[16] M. Pineda-Sanchez, M. Riera-Guasp, J. Roger-Folch, J. A. Antonino-Daviu, J. Perez-Cruz y R. Puche-Panadero, «Diagnosis of Induction Motor Faults in Time-Varying Conditions Using the Polynomial-Phase Transform of the Current,» IEEE Trans. Ind. Electron., vol. 58, n 4, 2011, pp. 1428-1439

[17] Riera-Guasp, M.; Pineda-Sanchez, M.; Perez-Cruz, J.; PuchePanadero, R.; Roger-Folch, J.; Antonino-Daviu, J.A.; , "Diagnosis of Induction Motor Faults via Gabor Analysis of the Current in Transient Regime,"Instrumentation and Measurement, IEEE Transactions on , vol.61, no.6, pp.1583-1596, June 2012

[18] Climente-Alarcon, V ; Antonino-Daviu, JA ; Riera-Guasp, M Puche-Panadero, R ; Escobar, L "Application of the Wigner-Ville distribution for the detection of rotor asymmetries and eccentricity through high-order harmonics" . Electric Power Systems Research Vol: 91 pp: 28, OCT 2012

[19] Bouzida, A.; Touhami, O.; Ibtiouen, R.; Belouchrani, A.; Fadel, M.; Rezzoug, A.; , "Fault Diagnosis in Industrial Induction Machines Through Discrete Wavelet Transform," IEEE Trans. Ind. Electron., vol.58, no.9, pp. 4385-4395, Sept. 2011.

[20] Kia, Shahin Hedayati; Henao, Humberto; Capolino, Gerard-Andre; "Windings monitoring of wound rotor induction machines under fluctuating load conditions ", IECON 2011 - 37th Annual Conference on IEEE Industrial Electronics Society, Melbourne, Australia, November 2011, Page(s): 3459 - 3465

[21] Y. Gritli, A. Stefani, C. Rossi, F. Filippetti, A. Chatti, "Experimental validation of doubly fed induction machine electrical faults diagnosis under time-varying conditions", Journal of Electric Power Systems Research, Vol. 81, Issue 3, pp. 751-766, March 2011.

[22] Gritli, Y.; Zarri, L.; Rossi, C.; Filippetti, F.; Capolino, G.; Casadei, D.; , "Advanced Diagnosis of Electrical Faults in Wound Rotor Induction Machines," Industrial Electronics, IEEE Transactions on vol. $60, \mathrm{n}^{\circ}$, September 2013, pp.4012-4024

[23] Vedreno-Santos, F., M. Riera-Guasp, H. Henao, M. PinedaSanchez, and J. A. Antonino-Daviu. "Diagnosis of eccentricity in induction machines working under fluctuating load conditions, through the instantaneous frequency", IECON 2012 - 38th Annual Conference on IEEE Industrial Electronics Society, October 2012.

[24] F. Vedreño-Santos, M. Riera-Guasp, H. Henao, M. PinedaSanchez, "Diagnosis of faults in induction generators under fluctuating load conditions through the instantaneous frequency of the fault components", XX International Conference on Electrical Machines (ICEM), 2012. Marseille

[25] A. Espinosa, J. Rosero, J. Cusido, L. Romeral, and J. Ortega, "Fault Detection by Means of Hilbert-Huang Transform of the Stator Current in a PMSM With Demagnetization," IEEE Trans. Energy Convers., vol. 25, pp. 312-318, 2010

[26] M. Pineda-Sanchez, M. Riera-Guasp, J. A. Antonino-Daviu, J. Roger-Folch, J. Perez-Cruz, and R. Puche-Panadero, "Instantaneous frequency of the left sideband harmonic during the start-up transient: A new method for diagnosis of broken bars," IEEE Trans. Ind. Electron., vol. 56, pp. 4557-4570, 2009.

[27] C.S. Burrus, R.A. Gopinath, H. Guo, Introduction to Wavelets and Wavelet Transforms a Primer, Prentice-Hall, Englewood Cliffs, NJ,

[28] Kia, S.H.; Henao, H.; Capolino, G.-A.; , "Diagnosis of BrokenBar Fault in Induction Machines Using Discrete Wavelet Transform Without Slip Estimation," Industry Applications, IEEE Transactions on , vol.45, no.4, pp.1395-1404, July-aug. 2009

[29] Cohen, J., Cohen P., West, S.G., \& Aiken, L.S. (2003). Applied multiple regression/correlation analysis for the behavioral sciences. (2nd ed.) Hillsdale, NJ: Lawrence Erlbaum Associates

[30] Cohen, J. (1988)."Statistical power analysis for the behavioral sciences (2nd ed.)" Hillsdale, NJ: Lawrence Erlbaum Associates.

[31] Gonzalo-Abad, J.; López, M.R.; Marroyo, L; Iwanski, G; "Doubly Fed Induction Machine: Modelling and Control for Wind Energy Generation", Vol. 85 IEEE Press Series on Power Engineering, John Wiley \& Sons, 2011, ISBN: 978111810495
[32] S. Nandi and H. A. Toliyat, "Condition monitoring and fault diagnosis of electrical motors-A review," IEEE Trans. Energy Convers., vol. 20,no. 4, pp. 719-729, Dec. 2005.

[33] J. Yun, K. Lee, K.W. Lee, S. B. Lee, and J. Y. Yoo, "Detection and classification of stator turn faults and high-resistance electrical connections for induction machines," IEEE Trans. Ind. Appl., vol. 45, no. 2, pp. 666-675,Mar./Apr. 2009.

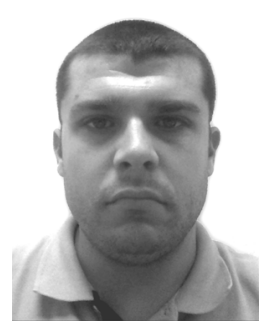

Francisco Vedreño-Santos received the M.Sc degree in electrical engineering from Universidad Politecnica de Valencia, Spain, in 2008, where he is currently working toward the Ph.D. degree in electrical engineering in the Departamento de Ingeneria Eléctrica. His research interests include electric-machine diagnostics, condition monitoring of electric machines and windmills.

Martín Riera-Guasp (M'94-SM'12) received the M. Sc. degree in industrial engineering and the Ph.D. degree in electrical engineering from the Universitat Politècnica de València, Valencia (Spain), in 1981 and 1987 respectively.

Currently, he is an Associate Professor with the Department of Electrical Engineering, Polytechnic University of Valencia. His research interests include condition monitoring of electrical machines, applications of signal analysis techniques to electrical engineering and efficiency in electric power applications.

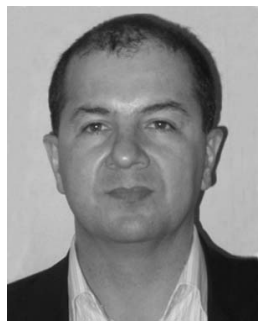

Humberto Henao (M'95-SM'05) received the M.Sc. degree in electrical engineering from the Technological University of Pereira, Pereira, Colombia, in 1983, the M.Sc. degree in power system planning from the Universidad de los Andes, Bogotá, Colombia, in 1986, and the $\mathrm{Ph} . \mathrm{D}$. degree in electrical engineering from the Institut National Polytechnique de Grenoble, Grenoble, France, in 1990. From 1987 to 1994, he was a Consultant for companies such as Schneider Industries and GEC Alstom in the Modeling and Control Systems Laboratory, Mediterranean Institute of Technology, Marseille, France. In 1994, he joined the Ecole Supérieure d'Ingénieurs en Electrotechnique et Electronique, Amiens, France, as an Associate Professor. In 1995, he joined the Department of Electrical Engineering, University of Picardie "Jules Verne," Amiens, as an Associate Professor, where he has been a Full Professor since 2010. He is currently the Department Representative for international programs and exchanges (SOCRATES). He also leads the research activities in the ?eld of condition monitoring and diagnosis for power electrical engineering. His main research interests are modeling, simulation, monitoring, and diagnosis of electrical machines and drives.

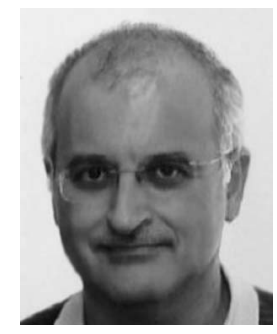

Manuel Pineda-Sanchez (M'02) received the Dipl. Ing. And Dr. Ing. degrees in electrical engineering from the Universidad Politécnica de Valencia, Valencia, Spain, in 1985 and 2004, respectively. He joined the faculty of the Universidad Politéc nica de Valencia in 1987 as an Associate Professor in the area of theory and control of electrical machineswith the Department of Electrical Engineering. His research interests include electrical machines and drives, induction motor diagnostics, numerical simulation of electromagnetic fields, and software development

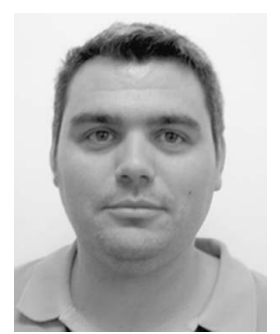

R. Puche-Panadero (M'09) received the M.Sc. degree in automatic and electronic engineering from the Universidad Politécnica de Valencia, Valencia, Spain, in 2003. From 2003 to 2006, he worked in an Innovate European Automation Project as a Developer of the SCADA programs and control panels. He joined the Universidad Politécnica de Valencia in 2006 and is currently an Assistant Professor of machine control.His research interests focus on induction motor diagnostics and maintenance, numerical modeling, and automation of industrial installations 